\title{
Health team for the elderly: a feasibility study for preventive home visits
}

\author{
Berit Seiger Cronfalk ${ }^{1,2,3}$, Astrid Fjell $^{2,3}$, Nina Carstens ${ }^{4}$, Lars Malvin Kvinge Rosseland ${ }^{5}$ Arvid Rongve $^{6}$, \\ Dag-Helge Rönnevik ${ }^{7}$ Åke Seiger ${ }^{3}$, Knut Skaug ${ }^{8}$, Karen Johanne Ugland Vae ${ }^{2}$, Marianne Hauge Wennersberg ${ }^{5}$ \\ and Anne-Marie Boström ${ }^{2,3,9}$
}

${ }^{1}$ Department of Nursing Sciences, Ersta Sköndal Bräcke University College, Stockholm, Sweden

${ }^{2}$ Department of Nursing, Western Norway University of Applied Sciences, Haugesund, Norway

${ }^{3}$ Department of Neurobiology, Care Sciences and Society, Karolinska Institutet, Stockholm, Sweden

${ }^{4}$ Pharmaceutical Services Advisor, Hospital Pharmacies Enterprise, Haugesund, Norway

${ }^{5}$ FOUSAM, Stord Haugesund University College, Haugesund, Norway

${ }^{6}$ Department of Psychiatry, Haugesund Hospital, Institute of Clinical Medicine, University of Bergen,

Bergen, Norway

${ }^{7}$ Department of Integrated Health Care, Helse Fonna Haugesund Hospital, Haugesund, Norway

${ }^{8}$ Department of Medicine, Helse Fonna Haugesund Hospital, Haugesund, Norway

${ }^{9}$ Department of Geriatric Medicine, Danderyd, Sweden

\begin{abstract}
The aim was to describe the development, utilization and feasibility of a model of preventive home visits, in an urban and a rural municipality in Norway. Background: Older people $>65$ years will rise significantly in coming years. Increased age is associated with risk of disability, illness and need for public health services. Preventive home visits is assumed to help older people to maintain their functional level longer, delaying disease and thus delaying the need for health care. Method: Descriptive explorative design describing the development, utilization and feasibility of preventive home visits in two different settings. All 77-year-old persons living at home in an urban municipality and all 75 years and older in a rural municipality were invited to participate. A questionnaire including a substantial number of tests concerning; fall, nutrition, polypharmacy and cognitive impairment was used by Health Team Nurses as base for a risk assessment. Pilot studies were conducted to validate the questionnaire including an inter-rater reliability study of the risk assessment tool. A multiprofessional team, Health Team for the Elderly met each week to evaluate risk assessments and make recommendations to be sent to each respective general practitioner. Data were analysed using descriptive and inferential statistics. In total, 167 persons (109 from the urban municipality and 58 from the rural municipality) participated, corresponding to $60 \%$ of the approached individuals. The mean time for the visits was 108 minutes (SD 20). Missing data were identified for; Do you feel safe in your municipality $(17.5 \%)$ and Are you looking forward to ageing (11.4\%). In total, 36 persons $(21.7 \%)$ were identified with increased risk for developing illness. We suggest that a structured model of preventive home visits and collaboration between highly specialized health care professionals are important factors for reliable health promoting risk assessments of elderly home dwellers.
\end{abstract}

Key words: elderly; home visits; risk assessment; self-evaluation; team

Received 15 April 2016; revised 8 July 2016; accepted 29 December 2016;

first published online 20 February 2017

Correspondence to: Berit Seiger Cronfalk, Ersta Sköndal University College, Stigbergsgatan 30, PO11189, 10061 Stockholm, Sweden. Email: berit.seiger-cronfalk@esh.se 


\section{Background}

Older people $\geqslant 65$ years are estimated to increase from 524 million today nearly 1.5 billion in 2050 and most prominently in the developing countries (Chatterji, 2013). Given that increased age is associated with declining health due to various illnesses, disabilities and general age-related functional impairment will leave older people especially vulnerable (Clegg et al., 2013). The gradually altering situation will also be a challenge to the health care systems (Rechel et al., 2013).

In 2012, the Norwegian government proclaimed a national strategy 'The Coordination reform' (Omsorgsdepartmentet, 2009). The purpose was to transfer the responsibility for the care of older and chronically ill people from state level to the local municipalities who would receive the main part of the financial compensation from the Norwegian government. A vital element in the reform was a change in the financial system involving municipality co-funding the specialist health care services. In order to find sustainable models facilitating the care transitions between the health care organizations and municipalities, partnerships or cooperation models have been encouraged by funding from the Norwegian government as they fortified the municipalities and hospitals for this purpose. In the western region of Norway, three state-run hospitals, 19 municipalities and Stord Haugesund University College organized a project in 2010 to facilitate this cooperation focussing on areas associated with care of older and chronically ill people. The region has a population of 170000 inhabitants and the size of the 19 municipalities vary between 216 and 45000 inhabitants. The main purpose of the collaboration project Helsetorgmodellen (www.helsetorgmodellen.no) was to establish a joint research and development department and to facilitate understanding and knowledge and define areas of responsibility between the three parties. This unique collaboration between academia and the health care system is a front-runner and has gained nationwide acknowledgement and serves as a role model in Norway. The present report is the first scientific result of this collaboration.

Preventive home visits (PHVs) have been described as well-organized care pathways restoring functions and supporting coping strategies for individuals and facilitating common programmes for the health care service of older people (Vass et al., 2007; Lofqvist et al., 2012;
Behm et al., 2014). Studies show that comprehensive data were collected during a PHV as information about the older person's health was derived from multiple questions and assessments (Lofqvist et al., 2012; Behm et al., 2014).

Behm et al. (2014) showed that it is possible to delay declining health in people $\geqslant 80$ years of age by introducing PHV. Such PHV was presented as one single visit by someone from the multidisciplinary team giving advice about various activities and information about help and support in the local municipality. The multiprofessional and multidimensional approach was described as a success factor delaying ill health. Behm et al. (2013) also showed that PHV empower and strengthen older persons' confidence concerning how they experience their ageing process. To have a positive outlook on ageing has been identified as important and to have a negative perspective has been identified as a risk factor (Stewart et al., 2012). In Denmark, a yearly PHV has been offered to all persons between 75 and 80 years of age since 1998 . Trained registered nurses (RNs) conducted a standardized PHV focussing on specific signs concerning depression, cognitive dysfunction, medication and use of alcohol. If increased risks were assessed this was discussed with the elder general practitioner (GP) also trained by a specific education programme (Vass et al., 2002). Another approach to PHV has been described by Sherman et al. (2012), where a comprehensive questionnaire was sent out to nearly six hundred 75-year-old people in Sweden posing questions concerning socio-demographic data, general and specific questions about perceived health and health behaviour. Sherman et al. (2012) suggested that their findings could give support to primary care nurses when asking older people about their health and posing the right questions.

Studies indicate that the Comprehensive Geriatric Assessment (CGA) may identify older person's risk for mortality, hospitalization and/or need for municipal services. CGA is defined as a multidisciplinary diagnostic tool to identify processes concerning medical, psychosocial, and functional limitations among frail old persons (Stuck et al., 1993; Devons, 2002). The CGA includes validated questionnaires and tests concerning actitiviets of daily living (ADL), depression, cognitive function, nutrition, and social abilities (Stuck et al., 1993; Lee et al., 2007). Studies referring to models of PHV often include CGA. 
In conducting PHV a number of assessments using CGA are made by the multidisciplinary team and including expertise when necessary (Vass et al., 2007; Luck et al., 2013). The multidisciplinary approach is characterized by the summation from each discipline of the team towards common goals. Team members work within the boundaries of their professional practice; progress is discussed at team meetings, effective communication is considered vital and the client's role is minimal. Momsen et al. (2012) suggested that it is important for the team to adhere to its purpose in order to optimize the health care pathway.

Systematic reviews on PHV suggest that they are effective in recognizing the older persons' needs if the intervention is based on multidimensional assessment questionnaires and follow-up visits (Tourigny et al., 2015). However, Mayo-Wilson et al. (2014) concluded that reliable benefits of PHV were difficult to identify, mainly due to the variation in study designs, selected populations and implementation strategies of the PHV.

To summarize, the population is ageing worldwide, and evidence exists that multidisciplinary team assessments and CGA have a positive impact on outcomes for older adults with various illnesses/ disorders. There are also growing evidence that PHV could have an impact on preventing disease in older adults. This is in coherence with our intentions to prevent disease and identify risks. However, we have not been able to identify any publications describing the development and utilization of a model for PHV and testing the feasibility of such a model.

\section{Aim}

The aim of this study was to describe the development, utilization and feasibility of a model of PHVs, in an urban and a rural municipality in Norway.

\section{Method}

This study employs a descriptive explorative design describing the phases of development, utilization and feasibility of PHV in two different settings.

\section{Setting}

Two different settings were included; an urban municipality with $\sim 45000$ inhabitants and a rural municipality with nearly 1000 inhabitants. In the urban municipality, there were facilities of a large hospital and extensive health care services including geriatric specialist care and general practitioners, four nursing homes, a home care organization and an office for social affairs. In the rural municipality health care was provided by a general practitioner, primary care nurses, home care organizations and one nursing home.

\section{Phase 1: development of the PHV model and the HTE team}

The purpose of our PHV was to identify risks and thereby possibly prevent illness and/or functional decline early. The project plan developed over a period of several months. In Figure 1 the project organization is presented.

During the development phase health care professionals from the hospital and the two municipalities were identified. Initially, three RNs were employed as health team nurse (HTN) two in the urban municipality and one (later two) in the rural municipality. The HTNs were specialized in geriatric care or primary health care. The local GP at the rural municipality, who was the project leader, was also selected to be part of the health team for the elderly (HTE) team as was the senior geriatrician at the hospital. Further a pharmacist, a physiotherapist, an occupational therapist and a senior citizen where included. The study also included a project administrator at the office for social affairs, responsible for identifying home dwellers in the two municipalities appropriate for the inclusion criteria. The HTE met once a week at the hospital discussing older people that had been assessed with increased risk by the HTN. The local GP was contacted by telephone and invited to take part in the meeting. The HTN presented the case and the risk score was discussed and evaluated by the whole team. Written recommendations from the HTE were thereafter sent to the GP.

The questionnaire. In the present study, a modified questionnaire inspired by Säätelä and Fagerström (2006) was used to assess the older person's health and risk for illness. The questionnaire included a substantial number of questions and tests concerning the four focal areas fall, nutrition, polypharmacy and cognitive impairment. In addition, the questionnaire also aimed at evaluating resources and challenges in daily life such as perceived general health, physical function or 


\begin{tabular}{|c|c|c|}
\hline Project group & Reference group & Health team for the elderly (HTE) \\
\hline $\begin{array}{l}\text { - a general practitioner (GP) } \\
(\mathrm{M})^{\star \star \star} \text { PROJECT LEADER } \\
\text { - one senior physician and } \\
\text { specialist in geriatrics }(\mathrm{H})^{\star} \\
\text { - one senior adviser and } \\
\text { professor in geriatrics }(\mathrm{U})^{\star \star} \\
\text { - a PhD, senior nurse and } \\
\text { head of R\&D }(\mathrm{U})\end{array}$ & $\begin{array}{l}\text { - one senior physician and } \\
\text { specialist in geriatrics }(\mathrm{H}) \\
\text { - one senior adviser and } \\
\text { professor in geriatrics }(\mathrm{U}) \\
\text { - a general practitioner } \\
(\mathrm{GP})(\mathrm{M}) \\
\text { - a PhD, senior nurse and } \\
\text { head of R\&D (U) } \\
\text { - a senior adviser social affairs } \\
\text { (H) } \\
\text { - a nursing home manager (M) } \\
\text { - a senior adviser and head of } \\
\text { finances (H) } \\
\text { - an administrator from the } \\
\text { coordination office (H) } \\
\text { - a representative from each } \\
\text { municipality (M) } \\
\text { - a senior nurse from the } \\
\text { geriatric ward (H) }\end{array}$ & $\begin{array}{l}\text { - a general practitioner } \\
\text { (GP)(M) HEALTH TEAM } \\
\text { LEADER } \\
\text { - one senior physician and } \\
\text { specialist in geriatrics }(\mathrm{H}) \\
\text { - a senior adviser social affairs } \\
\text { (H) } \\
\text { - a senior nurse from the } \\
\text { geriatric ward }(\mathrm{H}) \\
\text { - one RN (H/HTN } \\
\text { - three RN's(M/HTN) } \\
\text { - one senior pharmacist }(\mathrm{H}) \\
\text { - one nutrition specialist }(\mathrm{H}) \\
\text { - one physiotherapist }(\mathrm{H}) \\
\text { - one occupational therapist } \\
\text { (H) } \\
\text { - one senior citizen(M) }\end{array}$ \\
\hline
\end{tabular}

${ }^{\star} \mathrm{H}=$ Hospital, ${ }^{* *} \mathrm{U}=$ University College, ${ }^{* \star *} \mathrm{M}=$ Municipality, ${ }^{* \star *} \mathrm{HTN}=$ Health team nurse

Figure 1 Project organization. $\mathrm{H}=$ hospital, $\mathrm{U}=$ university college, $\mathrm{M}=$ municipality, $\mathrm{HTN}=$ health team nurse

\begin{tabular}{|l|l|l|}
\hline \multicolumn{1}{|c|}{ Demographic } & \multicolumn{1}{|c|}{ Health assessment } & \multicolumn{1}{|c|}{ Risk assessment score } \\
\hline - Gender & - Perceived health (SF-36) & - Declining health \\
- Age & - Perception on life (PLOS) & - Declining functional level \\
- Education & - Physical activities & - Loneliness \\
- Social status & (Barthel ADL Index) & - Risk of falling \\
- Family and friends & - Risk of falling (BBS) & - Recently moved \\
- Housing arrangements & - Nutritional status (MNA) & - Declining sight/hearing \\
- Social support (OSLO-3SSS) & - Pain (VAS) & - Loss of close one \\
& - Cognition (optional to & - Spouse is chronically ill \\
& answer Mini-Cog) & - Recently discharged from \\
& - Various questions & hospital \\
& concerning health, & - Mental or cognitive \\
& illness and medication & problems \\
& & - Polypharmacy \\
& & BMl and nutrition \\
\hline
\end{tabular}

Figure 2 Assessment tools and examples of questions. The following validated instruments were included: Perceived health Short Form-36 (SF-36, Sullivan et al., 1995), PLOS (Deaton and Paxson, 1998), Barthel ADL Index and questions concerning the older persons activity in daily life (Hartigan, 2007), Risk of falling Bergs Balance Score (BBS) (Berg et al., 1992), nutritional status Mini Nutritional Assessment (MNA) (Kaiser et al., 2009), level of pain (visual analouge scale - VAS) (Revill et al., 1976) and cognitive decline or impairment, Mini-Cog (Borson et al., 2000); OSLO 3-Social Support Scale (OSLO 3-SSS) (Meltzer, 2003).

disability, illness, lifestyle and social network. Further, questions posed included use of nonprescriptive drugs and products concerning complementary and alternative medicine and standard of living.

The project group developed a risk assessment score summarizing 12 topics into subscales from the questionnaire (Figure 2). The HTN scored each topic on a response risk scale; $0=$ no risk,
$1=$ of no importance, $2=$ of some importance, $3=$ of importance, $4=$ of significant importance and $5=$ of paramount importance. The scores for each of the subscales were summarized by the HTN following the PHV. The total scores were categorized in levels:

1. 0-24: no immediate risk of illness and/or reduced functional level.

Primary Health Care Research \& Development 2017; 18: 242-252 
2. 25-36: some risk for developing illness and/or functional decline.

3. 37-48: increased risk for developing illness and/ or functional decline.

4. 49-60: high risk for developing illness and/or functional decline.

If a person was assessed at Level 2-4 he/she was discussed at the HTE meeting.

Pilot tests of the questionnaire. During phase 1 a pilot study (not included in later data collection) was conducted to validate the questionnaire and risk assessment procedure including 10 older persons from the urban municipality. In addition, to answer the questionnaire the participants were asked to contribute with their views on the questions.

Furthermore, to examine inter-rater reliability of the HTNs' risk assessment scores an additional 20 visits to older people at the age of 78 were performed by the HTNs in the urban municipality. During the visits the HTNs acted as either facilitator or moderator, posing additional questions if needed. Following the visits the HTN independently assessed the older person's risks according to the risk assessment tool.

Promotion of the PHVs. During phase 1, extensive promotion of the project was carried out in both communities. Media were contacted and hearings about the project were arranged. Older people, GP's and politicians were invited to receive information about the project from the HTE team.

\section{Phase 2: utilization of the PHV model}

Recruitment procedure. All 77-year-old persons living at home in the urban municipality $(n=177)$ and those 75 years and older in the rural municipality $(n=82)$ were invited to participate, irrespective of whether they received home assistance from the municipalities or not. Exclusion criteria were; living in a nursing home or lacking the ability to communicate in the Norwegian language.

The target group was identified by the Norwegian population register. An invitation and information letter was sent to all in the target group, inviting them to participate in one PHV. The letter explained the purpose of the PHV. The information also included clarifying instruction about how to decline participation, by calling the administrator. The information also explained that participation in the research study was voluntary. This was followed by a telephone call from the project administrator at the centre for social affairs. Following the responses from the participants, the project administrator made arrangements concerning the $\mathrm{PHV}$, that is made reservation for the visit, and gave the name of the HTN performing the visit. A folder with further information was sent out including a presentation and photo of the HTNs making the visits.

During the PHV, HTN used the questionnaire to assess health and risk for illness. Also, blood pressure, heart rate and body mass index (BMI) were registered. The HTN also made recommendations about increased lighting when necessary. If risks were identified the person was informed that it would be a matter for the HTE team to discuss as well as notifying the GP. Following the visit the persons were encouraged to contact the HTNs if they wanted to add something. All were given telephone numbers for contact. Older persons in the urban municipality had no prior personal relationship or knowledge of the HTN while in the rural municipality the HTN was well known to the majority of participants.

Data management and analysis. Data were entered, managed and analysed in SPSS by a research assistant and analysed by descriptive and inferential statistics using Student's $t$-test and $\chi^{2}$ test. To test the inter-rater reliability of the assessment of risk score Cohen's $\kappa$ test was used (Landis and Koch, 1977).

\section{Results: the feasibility of the PHV model}

\section{Description of sample}

A total of 259 persons were invited, 145 (60\%) accepted participation; 87 (49\%) in the urban and 58 $(71 \%)$ in the rural municipality. In addition, the 20 persons who participated in the inter-rater reliability test were included into the sample of the study and two persons who turned 78 years in the urban municipality were also included, thus the sample consists of 167 persons with 109 persons from the urban municipality and 58 persons from the rural municipality. One of the persons in the urban municipality partly participated in the PHV but 
the questionnaire was not completed. Thus questionnaires from 166 persons have been used in the analysis. Of the 166 participants, $96(57.8 \%)$ were women and $70(42.8 \%)$ were men, and the mean age was 78.7 years. In the urban municipality, 61 (56.5\%) were women and $47(43.5 \%)$ were men, and the mean age was 77.3 years. In the rural municipality, $35(60.3 \%)$ were women and $23(39.7 \%)$ were men, and the mean age was 81.4 years. A significant difference was identified between the urban and rural samples regarding age (urban $m=77.3$ versus rural $m=81.4$; $t$-test $=-6.848 ; P$-value $<0.001)$.

Of the 114 persons who declined participation $45(39 \%)$ were men and $68(60 \%)$ women (one unknown). No statistical difference concerning gender was identified between the two municipalities or between the study sample and those who did not participate. The reasons for persons declining participation are presented in Table 1. For example, seven participants (four urban and three rural) participated in the PHV but declined participation in the study. The majority of people declining participation described that they were in good health and thought it unnecessary to take part. Others expressed that they had no wish to have contact with representatives from the municipality.

\section{The time for conducting the PHV}

The time spent on the PHV in-home visits varied between 60 and $180 \mathrm{~min}(n=149)$, and the mean time was $108 \mathrm{~min}$ (SD 20). There was a significant difference between the duration of the PHV in the two municipalities. In the urban municipality, the mean time was $(n=91) 112 \mathrm{~min}$ (SD 20) compared with the time for the PHV in the rural municipality $(n=58) \quad$ being $102 \mathrm{~min} \quad(\mathrm{SD} 19) \quad(t=3.062$; $P=0.003)$. At the end of the PHV the participants $(n=156)$ were asked whether they desired a second visit. Of the 156 participants 150 replied that they were interested. The results show no difference between the municipalities or between men and women in this regard. To validate these results letters were sent posing the same question at a later date with a positive response rate of $70 \%$.

\section{Missing data in the questionnaire}

The data were collected from the 166 persons during the PHV by four HTNs using the previously

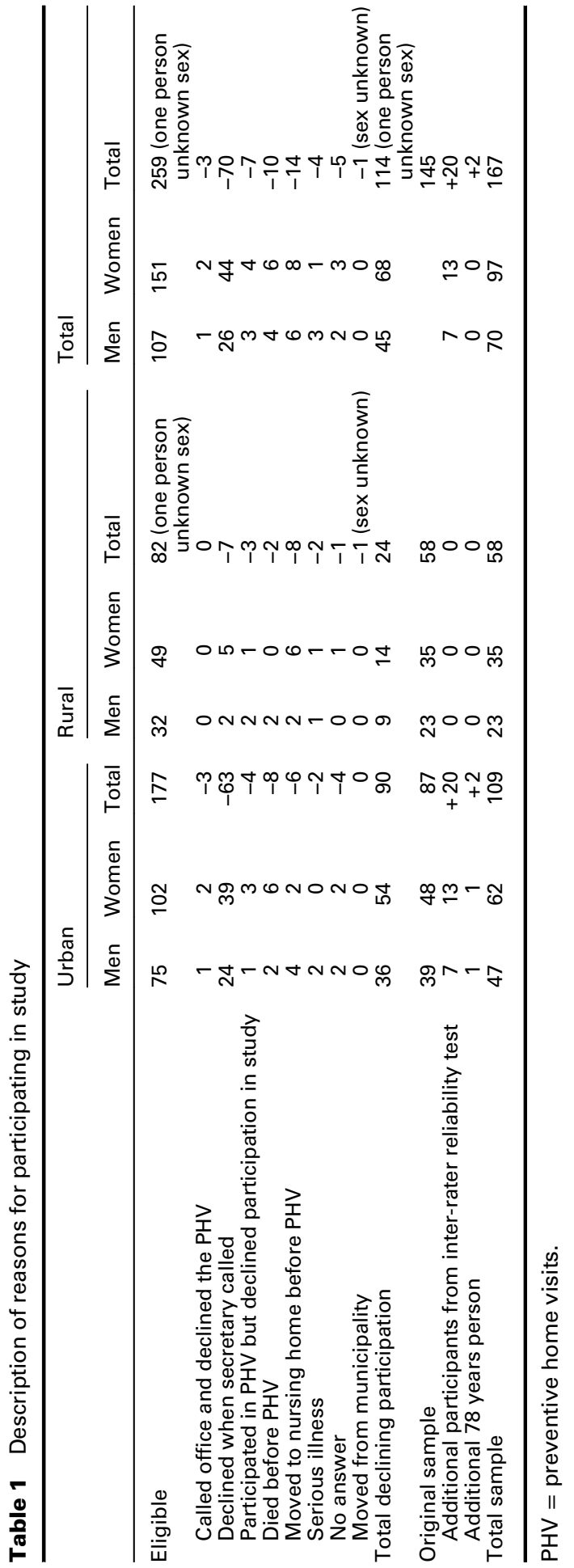

Primary Health Care Research \& Development 2017; 18: 242-252 
described instrument. Missing data varied depending on part of the survey, between 0 and $17.5 \%$. No missing data were identified for demographic variables (age, gender, civil status, living alone yes/ no, children).

For the section Health assessment the missing data were mostly regarding the questions on Relationships and social network and the Balance test. In total, $29(17.5 \%)$ persons did not respond to the alternatives on the question do you feel safe in your municipality and 19 (11.4\%) persons did not respond to the question are you looking forward to ageing. The missing data were mainly from the persons living in the urban area. Seven (4.2\%) persons did not complete the test Bergs Balance Score test due to difficulties to conduct the test.

\section{Inter-rater reliability}

In Table 2 the findings from the inter-rater reliability test are presented. High correlations between the HTN observations were true for eight of the 12 subscales and very high for the total risk assessment level.

\section{Risk assessment of the older persons}

In Table 3 results from the risk assessments are presented. The total risk assessment score for the total sample was 15.7 (SD 7.1). Of the 166 persons $130(78.3 \%)$ persons were categorized into Level 1, $27(16.3 \%)$ persons were categorized into Level 2 , and nine $(5.4 \%)$ persons were categorized into

Table 2 Inter-rater reliability analysis of the risk assessment score (total score and subscales)

\begin{tabular}{ll}
\hline Subscales for risk assessment & $\begin{array}{l}\text { Cohen's } \\
\kappa\end{array}$ \\
\hline 1. Declining health & 0.802 \\
2. Decline in functional level & 0.776 \\
3. Loneliness & 0.285 \\
4. Risk of falling/dizziness & 0.703 \\
5. Recently moved & - \\
6. Declining sight/hearing & 0.762 \\
7. Loss of close one & 0.519 \\
8. Spouse is chronically ill & 0.710 \\
9. Recently discharged from hospital & 0.318 \\
10. Mental or cognitive problems & 0.839 \\
11. Polypharmacy = more than four & 0.842 \\
prescription medications & \\
12. BMl < 20 and/or weight loss $>10 \%$ & 0.727 \\
Risk assessment level & 0.912 \\
\hline
\end{tabular}

Primary Health Care Research \& Development 2017; 18: 242-252
Level 3 representing increased risk for developing illness. There were no significant differences between the two municipalities in this regard.

The $36(21.7 \%)$ persons who were identified at Levels 2 and 3 were discussed in meetings with the HTE team. For the older persons living in the rural municipality the project leader was the GP for these persons. For the older persons living in the urban municipality each person's GP was invited but no GP participated in the HTE meeting. Instead written feedback from the team was sent to the GP.

\section{Discussion}

The organization of the project was to include stakeholders from the three different parties involved in the Coordination reform namely the municipalities, the hospital and the university college. To involve actively the stakeholders must be considered instrumental in this context. The intention with the reform was to facilitate collaboration across the regional sectors at a time when the municipalities took over the main responsibility for care of frail and old people. Another beneficial aspect was the collaboration between the health professionals and representation from academia as they were all included in the organization of the study process and testing the questionnaire. Vass et al. (2005) showed the importance of such an approach. A weakness that may be considered in future studies was the lack of spokespersons representing the older population in the reference and project groups. This might have impacted on the number of participants in the study particularly in the urban municipality. The participation from the local GPs was low and should be considered in the future as their involvement could be pivotal for the organization of PHV. Their involvement should have been considered early in the planning process of the project. In previous studies the primary care organizations were described as responsible for conducting PHV (Vass et al., 2007; Sherman et al., 2016) that might have a positive bearing on their engagement.

In the promotion of the PHV the project group conducted meetings in the two municipalities where they participated and included mass media. This arrangement was a formal dissemination of the news to the older population and the structure of the meetings was similar in both municipalities. 
Table 3 Risk assessment score (total score and categorized in risk levels) for the total sample and samples from the two municipalities

\begin{tabular}{|c|c|c|c|c|c|}
\hline & $\begin{array}{l}\text { Total sample } \\
(n=166)\end{array}$ & $\begin{array}{l}\text { Urban municipality } \\
(n=108)\end{array}$ & $\begin{array}{l}\text { Rural municipality } \\
(n=58)\end{array}$ & $\begin{array}{l}\text { Statistical } \\
\text { test }\end{array}$ & $P$-value \\
\hline Total score $[m(S D)]$ (min: 0, max: 60) & $15.7(7.1)$ & $16.4(6.4)$ & $14.4(8.0)$ & \multirow{4}{*}{$\begin{array}{c}\mathrm{t}=1.759 \\
\chi^{2}=1.407 \\
\text { d.f. }=2\end{array}$} & \multirow{4}{*}{$\begin{array}{l}0.08 \\
0.495\end{array}$} \\
\hline $\begin{array}{l}\text { Level } 1 \text { no immediate risk of illness } \\
{[n(\%)](\text { min: } 0, \text { max: } 24)}\end{array}$ & $130(78.3 \%)$ & $83(76.9 \%)$ & $47(81 \%)$ & & \\
\hline $\begin{array}{l}\text { Level } 2 \text { some risk for developing illness } \\
{[n(\%)](\min : 25, \text { max: } 36)}\end{array}$ & $27(16.3 \%)$ & $20(18.5 \%)$ & $7(12.1 \%)$ & & \\
\hline $\begin{array}{l}\text { Level } 3 \text { increased risk for developing } \\
\text { illness }[n(\%)] \text { (min: } 37, \max : 48)\end{array}$ & $9(5.4 \%)$ & $5(4.6 \%)$ & $4(6.9 \%)$ & & \\
\hline
\end{tabular}

However, there was probably a stronger informal dissemination in the rural municipality where the GP was the project leader for the PHV project and the HTN was employed as one of the home care nurses. These persons were well known in the rural area among the older persons, and they were also the health care providers for the population since many years. In the urban municipality, the HTNs were employed by the municipality but did not have their work places/offices within the home care organization with other home care nurses and GPs. This lack of informal networking and dissemination of the new PHV among the health care providers in the home care organization in the urban municipality may have impacted on the recruitment of older persons to the PHVs.

The project group decided to use a previously developed and validated questionnaire for PHV. The literature on CGA strongly advocates using multidisciplinary instruments assessing various aspects of health and risk factors of illness for the older persons (Devons, 2002). However, there is a lack of knowledge on how to weigh the information from included instruments into a summarized risk score. It is common to distinguish between two categories of risk; positive and constructive. The scientific interpretations range from the strictly positive view of risk as a probability or frequency, to the culturally or constructive interpretation where risk makes sense within a social context (Kaplan and Garrick, 1981). The risk assessment used in this PHV model has elements of both a positive and a constructive view. Parts of the risk mapping is based on validated tests, where the HTN scores depending on how much the older person is able or unable to perform the test, which speaks for a positive view of risk. Risk factors such as Loneliness, Recently moved, Loss of close one and Spouse is chronically ill can provide the basis for a constructive risk assessment of the older person. In this project, we developed a risk assessment score combining the responses from the validated instrument and the implicit information from the interviews which the HTN evaluated using the response scale for each of the 12 subscales. The findings from the inter-rater reliability test showed mostly high correlations for the subscales; however, for the subscales Loneliness, Loss of close one and Recently discharged from hospital the correlations were weaker. One explanation for these findings might be that the two HTNs interpreted the situation for the older person in different ways such as whether loneliness was a risk for illness or not. It is of interest to understand how the HTNs interpreted the situation, which information influenced their scoring of the risk for the older person, and whether this tacit knowledge could be described and understood. This part of the questionnaire needs more psychometric testing and evaluation in future studies.

The majority of the persons who declined PHV said they were 'too healthy' to participate. This is completely in line with what the participants in the study by Vass et al. (2002) and Sherman et al. (2016) specified as a reason to reject. It was the rural municipality that had a higher participation percentage $(71 \%)$ compared with that of the urban municipality $50 \%$. According to National Center for Health Statistics (CDC, NCfHS, 2002) rural populations are often less engaged in health promotion activities, such as physical exercise or screening tests compared with their urban counterparts. This was not the case in the rural municipality in this study which might be explained by the close collaboration with the health care providers there. According to Toien et al. (2014) older persons consider the PHV to generate a sense of security. 
It is possible that a familiar nurse triggered a sense of security, which promoted the older person to accept the visit. Furthermore, the sample in the rural group was significantly older than the rural group which might have increased the interest to participate.

In the total sample, $21 \%$ of the persons were identified with some or increased risk for developing illness. In a previous study by Sherman et al. (2012) on this age group the percentage of persons identified to be at risk was $14 \%$ in comparison with the present study. In the present study the design was the same for both locations, even though partly different age cohorts. Even if the age group in the rural community was significantly older, there was no significant difference in proportion of being at risk for developing illness (Table 2). Also, no followup visit was planned even though most participants were positive to receive PHV in the future. It is therefore impossible to know if the PHV had positive effects on the participants' health and if they conformed to the recommendations given.

Finally, the multidisciplinary approach is to work towards common goals, Momsen et al. (2012) suggest that it is of importance that the team is flexible in order to optimize the health care pathway. In the present study the team members' common goal was to investigate and assess possible risks and generate valid preventive aspects and/or treatment for older people living at home. A common understanding is that teamwork contributes to extending each member's competence within the geriatric field and could be described as educational supervision of the professionals and experts. This is in line with Momsen et al. (2012) as they claim the importance of a team's skills to adapt as necessary to optimize PHV. The present study showed elements of interdisciplinary team, characterized by the team members' willingness to share knowledge, rely on each other's decisions and influencing each other's decisions. According to Johansson et al. (2010) team members who share each other's expertise contribute to forming an effective team. The multidisciplinary HTE in our study generated comprehensive expertise in areas concerning older persons and PHV.

\section{Limitation of the study and further research}

Regarding the design of this study the risk of bias must be taken into consideration as the HTN in the rural municipality already knew the participants. Another aspect to consider is that no follow-up visits were planned. It is therefore impossible to know if the recommendations given to the participants following the PHV were met. Toien et al. (2014) found that older people who received one single PHV visit often misunderstood the purpose of the visit. The participants considered given information as ambiguous, and difficult to understand. Previous studies concerning PHV have described communication skills as a prerequisite; still few studies explain its implications (Elkan et al., 2001; Avlund et al., 2007). In the literature health literacy (HL) is described as the ability of the individual to obtain and understand basic health information appropriate for the individual's health decisions. Sorensen and Brand (2014) identified $\mathrm{HL}$ as a multidimensional concept consisting of different components. Based on their findings they developed an integrated model of HL. The central aspect of the HL model is that a person needs competence both to seek, comprehend, interpret and use health information. Good health communication skills among health professionals that take into account a person's HL level, have the potential to increase knowledge, and improve attitudes and skills of the individual. This in turn may lead to higher compliance and better self-management (Dewalt et al., 2004). In forthcoming studies participants' HL should be assessed in conjunction with the PHV to increase the awareness for the nurse and to facilitate the communication to ensure the participant's degree of understanding the information and recommendations given during the PHV. In the present study, we did not take into account the participants' degree of understanding the information and recommendations given during the $\mathrm{PHV}$ visit.

\section{Conclusions}

The aim of this study was to describe the development, utilization and feasibility of a model of PHVs in an urban and a rural municipality in Norway. Our results show that the PHV model was feasible and $60 \%$ of eligible persons accepted participation. We identified one-fifth of the participants at risk of failing health and reported recommendations from the HTN assessments and team evaluations to the GPs. We also show that a structured model and collaboration between highly specialized professionals is important for this purpose. 


\section{Acknowledgements}

The authors wish to thank Börje Bjelke, Geir Sverre Braut and Arvid Birkeland for contributing their specialist knowledge.

\section{Financial Support}

The project received financial support from the regional collaboration, Helsetorgmodellen.

\section{Conflicts of Interest}

The authors declare that they have no conflicts of interest with respect to the research, authorship and/or publication of this article.

\section{Ethical Standards}

The authors assert that all procedures contributing to this work comply with the ethical standards of the relevant national and institutional guidelines on human experimentation by the Norwegian Social Sciences Data Services A/S NSD (no. 29153) and with the Helsinki Declaration of 1975 , as revised in 2008.

\section{References}

Avlund, K., Vass, M., Kvist, K., Hendriksen, C. and Keiding, N. 2007: Educational intervention toward preventive home visitors reduced functional decline in communityliving older women. Journal of Clinical Epidemiology 60, 954-62.

Behm, L., Ivanoff, S.D. and Ziden, L. 2013: Preventive home visits and health - experiences among very old people. $B M C$ Public Health 13, 378.

Behm, L., Wilhelmson, K., Falk, K., Eklund, K., Ziden, L. and Dahlin-Ivanoff, S. 2014: Positive health outcomes following health-promoting and disease-preventive interventions for independent very old persons: long-term results of the three-armed RCT Elderly Persons in the Risk Zone. Archives of Gerontology and Geriatrics 58, 376-83.

Berg, K., Wood-Dauphinee, S.L., Williams, J.I. and Maki, B. 1992: Measuring balance in the elderly: validation of an instrument. Can J Public Health 83, 7-11.

Broson, S., Scanlan, J., Watanabe, J., Tu, S. and Lessig, M. 2005: Simplifying detection of cognitive impairment: comparison of the Mini-Cog and Mini-Mental State Examination in a multiethnic sample. J Am Geriatr Soc 53, 871-74.

CDC, NCfHS 2002: Trends in health and aging. Retrieved 3 October 2016 from http://www.cec.gov/nchs/agingact.htm.
Chatterji, S. 2013: World Health Organisation's (WHO) Study on Global Ageing and Adult Health (SAGE). BMC Proceedings 7, S1.

Clegg, A., Young, J., Iliffe, S., Rikkert, M.O. and Rockwood, K. 2013: Frailty in elderly people. Lancet 381, 752-62.

Deaton, A.S. and Paxson, C.H. 1998: Aging and Inequality in Income and Health, American Economic Association, American Economic Review, 88, 248-53.

Devons, C.A. 2002: Comprehensive Geriatric Assessment: making the most of the aging years. Current Opinion in Clinical Nutrition and Metabolic Care 5, 19-24.

Dewalt, D.A., Berkman, N.D., Sheridan, S., Lohr, K.N. and Pignone, M.P. 2004: Literacy and health outcomes: a systematic review of the literature. Journal of General Internal Medicine 19, 1228-239.

Elkan, R., Kendrick, D., Dewey, M., Hewitt, M., Robinson, J., Blair, M., Williams, D. and Brummell, K. 2001: Effectiveness of home based support for older people: systematic review and meta-analysis. BMJ 323, 719-25.

Hartigan, I. 2007: A comparative review of the Katz ADL and the Barthel Index in assessing the activities of daily living of older people. Older People Nursing 2, 204-12.

Johansson, G., Eklund, K. and Gosman-Hedstrom, G. 2010: Multidisciplinary team, working with elderly persons living in the community: a systematic literature review. Scandinavian Journal of Occupational Therapy 17, 101-16.

Kaiser, M.J., Bauer, J.M., Ramsch, C., Uter, W., Gugoz, Y., Cederholm, T., Thomas, D.R., Anthony, P., Charlton, K.E., Maggio, M., Tsai, A.C. and Garthwohl, D. 2009: Validation of the Mini Nutritional Assessment short-form $\left(\mathrm{MNA}^{\circledR}-\mathrm{SF}\right)$ : A practical tool for identification of nutritional status. The Journal of Nutrition, Health \& Aging 13, 782-88.

Kaplan, S. and Garrick, B.J. 1981: On the quantitative definition of risk. Risk Analysis 1, 11-27.

Landis, J.R. and Koch, G.G. 1977: An application of hierarchical kappa-type statistics in the assessment of majority agreement among multiple observers. Biometrics 33, 363-74.

Lee, J.S., Potter, G.G., Wagner, H.R., Welsh-Bohmer, K.A. and Steffens, D.C. 2007: Persistent mild cognitive impairment in geriatric depression. International Psychogeriatric 19, 125-35.

Lofqvist, C., Eriksson, S., Svensson, T. and Iwarsson, S. 2012: First steps towards evidence-based preventive home visits: experiences gathered in a Swedish municipality. Journal of Aging Research 2012, 352942.

Luck, T., Motzek, T., Luppa, M., Matschinger, H., Fleischer, S., Sesselmann, Y., Roling, G., Beutner, K., Konig, H.H., Behrens, J. and Riedel-Heller, S.G. 2013: Effectiveness of preventive home visits in reducing the risk of falls in old age: a randomized controlled trial. Clinical Interventions in Aging 8, 697-702.

Mayo-Wilson, E., Grant, S., Burton, J., Parsons, A., Underhill, K. and Montgomery, P. 2014: Preventive home visits for mortality, morbidity, and institutionalization in older adults: a systematic review and meta-analysis. PLoS One 9, e89257. 
Meltzer, H. 2005: Development of a common instrument for mental health. In Nosikov, A.G.C., EUROHIS: Developing common instruments for health surveys. IOS Press, 35-60.

Momsen, A.M., Rasmussen, J.O., Nielsen, C.V., Iversen, M.D. and Lund, H. 2012: Multidisciplinary team care in rehabilitation: an overview of reviews. Journal of rehabilitation medicine 44, 901-12.

Omsorgsdepartmentet, H.-O. 2009: Samhandlingsreformen: rett behandling- på rett sted- till rett tid. Stort. meldn.

Rechel, B., Grundy, E., Robine, J.M., Cylus, J., Mackenbach, J.P., Knai, C. and Mckee, M. 2013: Ageing in the European Union. Lancet 381, 1312-322.

Revill, S. I., Robinson, J.O., Rosen, M. and Hogg, M.I.J. 1976: The reliability of a linear analogue for evaluating pain. Anaesthesia, 31, 1191-198.

Säätelä, S. and Fagerström, L. 2006: GERDA-projektet tvärvetenskaplig forskning om äldres livsvillkor över gränserna. Vård i Focus 23, 27-29.

Sherman, H., Forsberg, C., Karp, A. and Tornkvist, L. 2012: The 75-year-old persons' self-reported health conditions: a knowledge base in the field of preventive home visits. Journal of Clinical Nursing 21, 3170-182.

Sherman, H., Soderhielm-Blid, S., Forsberg, C., Karp, A. and Tornkvist, L. 2016: Effects of preventive home visits by district nurses on self-reported health of 75-year-olds. Primary Health Care Research and Development 17, 56-71.

Sorensen, K. and Brand, H. 2014: Health literacy lost in translations? Introducing the European health literacy glossary. Health Promotion International 29, 634-44.

Stewart, T.L., Chipperfield, J.G., Perry, R.P. and Weiner, B. 2012: Attributing illness to 'old age:' consequences of a selfdirected stereotype for health and mortality. Psychology and Health 27, 881-97.
Stuck, A.E., Siu, A.L., Wieland, G.D., Adams, J. and Rubenstein, L.Z. 1993: Comprehensive Geriatric Assessment: a meta-analysis of controlled trials. Lancet 342, 1032-36.

Sugimoto, Y., Negishi, M., Hayashi, Y., Na,ba, T, Honda, A., Watabe, A., Hirata, M., Narumiya, S. and Chikawa, A. 1993: Two isoforms of the EP3 receptor with different carboxyl terminal domains. J Biol Chem 268, $2712-718$.

Sullivan, M.J.L. and Bishop, S.R. 1995: The Pain Catastrophizing Scale; Development and Validation. Psychosocial Assessment, 7, 524-32.

Toien, M., Heggelund, M. and Fagerstrom, L. 2014: How do older persons understand the purpose and relevance of preventive home visits? A study of experiences after a first visit. Nursing Research and Practice 2014, 640583.

Tourigny, A., Bedard, A., Laurin, D., Kroger, E., Durand, P., Bonin, L., Sevigny, A., Frappier, A., Roussel, M.E. and Martin, M. 2015: Preventive home visits for older people: a systematic review. Canadian Journal on Aging 34, 506-23.

Vass, M., Avlund, K., Hendriksen, C., Andersen, C.K. and Keiding, N. 2002: Preventive home visits to older people in Denmark: methodology of a randomized controlled study. Aging Clinical and Experimental Research 14, 509-15.

Vass, M., Avlund, K., Hendriksen, C., Philipson, L. and Riis, P. 2007: Preventive home visits to older people in Denmark why, how, by whom, and when? Zeitschrift Fur Gerontologie Und Geriatrie 40, 209-16.

Vass, M., Avlund, K., Lauridsen, J. and Hendriksen, C. 2005: Feasible model for prevention of functional decline in older people: municipality-randomized, controlled trial. Journal of the American Geriatrics Society 53, 563-68. 